\title{
SUNDOWNING: EFFECTIVENESS OF TEACHING AMONG NURSING STUDENTS
}

\author{
Ms. Agnes Monica .V \\ Lecturer, Psychiatric Mental Health Nursing, \\ King Saud Bin Abdul Aziz University for Health Sciences, \\ Riyadh, Kingdom of Saudi Arabia. \\ yoguddi@gmail.com
}

\begin{abstract}
Alzheimer's disease is a major public health issue that will increasingly affect the health and well-being of the population. Memory disorders will become conventional, and there is an increased need for excellent health care services for the aged population. Developing positive attitudes towards people with Alzheimer's disease is necessary yet challenging. Nursing care plays crucial role in providing care for geriatric patients at hospital, community and at home because of the effects of aging and multiple co-morbid medical conditions. In general, nursing students spend significant periods of time on clinical placements. Also evidence suggests that the health services in developing countries were not adequately prepared to provide better services for people with Alzheimer's disease related dementia.
\end{abstract}

Objective. The study evaluated the nursing students' knowledge toward individuals with Alzheimer's disease.

Methodology. The research design used for the study was a preexperimental one group pre-test post-test carried out with a randomly selected group of nursing students $(\mathrm{N}=120)$ from Chennai, India. The study used the Alzheimer's disease Knowledge scale (30 questions).

Results. The analysis of the study findings revealed that there is a significant difference in the level of knowledge scores between the master degree and post basic, bachelor degree students. The mean knowledge score was $75.5 \pm 8.4$ slightly higher compared to the students from post basic and bachelor degree students.

Conclusion. The study concluded that the students had inadequate knowledge of Alzheimer's disease during the pre-test. However, they have some knowledge towards the same patients, giving way to improve their knowledge related to the disease after providing essential knowledge on the same. Thus, there is vital necessity to augment the nursing students study plan with respect to the content of the study and strengthen their knowledge of comprehensive care to individuals with Alzheimer's disease.

KEYWORDS: ALZHEIMER'S DISEASE; KNOWLEDGE; CROSSSECTIONAL STUDY; NURSING STUDENTS.

\section{BACKGROUND}

Alzheimer's disease is a major health problem worldwide and it is inevitable that nursing students on placement in facilities for the care of older people will regularly care for people who have
Alzheimer's disease related dementia. Alzheimer's disease is the most common form of dementia in the elderly and around $60-80 \%$ of all cases of dementia which is chronic progressive, irreversible degenerative disease of the brain. [21] It usually erupts with a symptom called Sun downing which is otherwise known as "late-day confusion." This dementia related symptom discusses to augmented agitation, confusion and hyperactivity that instigates in the late afternoon and constructs throughout the evening. The person who has dementia, will be in a state of confusion and agitation which may get poorer in the late afternoon and evening. In contrast, their symptoms may be less noticeable earlier in the day. Mostly sundowning emerges in mid-stage dementia and slowly worsens as the disease progresses where it may damage the body's internal clock, causing a disruption of sleep-wake cycles. Secondly, individuals with dementia become fatigued through their incompetence to run through information the extra hours consumed on this process, the more shattered and irritable they may develop [1].

Sundowning represents a relevant and challenging manifestation of Alzheimer's disease related dementia, happening in an outsized amount of exaggerated individuals and being concomitant with a substantial social and economic burden. Increasing our knowledge on how to recognize, approach, and accomplish sundowning might thus consent to meaningfully improve the welfare of patients and their care givers. Specifically, a greater effort is needed in order to disentangle and elucidate the complex and multifaceted pathophysiological bases of this phenomenon.[20] Dementia is a major health problem worldwide as there will be threefold increase in people living with dementia globally by 2050 [34]. Studies indicate that adequate knowledge of dementia is needed among health care professionals which is likely to affect critical issues in care and enhances better patient outcomes [26].

Like in other countries, in India a number of people with Alzheimer's disease and other dementias is expected to increase due to increase in longevity and increasing prevalence of risk factors such as hypertension, stroke and lifestyle changes. However, some studies indicate that healthcare provision for people with dementia, largely based on caregiver's time limitations, poor knowledge and lack of understanding about individual patient needs [29]. Age alone puts one at risk for Alzheimer's disease (AD) which is the most common type of dementia representing almost $80 \%$ of all dementias [2]. AD 
causes problems with memory, thinking, and behavior. Symptoms develop slowly, get worse over time [3], and significantly affect every health system in the world. An estimated 5.4 million Americans have Alzheimer's disease and by 2030, the number of people aged 65 and older with $\mathrm{AD}$ will reach 7.7 million, a $50 \%$ increase. Furthermore, more than $25 \%$ of all hospital patients over the age of 65 may have Alzheimer's disease [2].

Numerous studies examined nursing student's knowledge towards the older adult population. Care of older adults can be compromised, and requisite care denied due to negative attitudes [23]. In acute care settings, nursing staff lacked the necessary knowledge and skills to provide person centered care for patients with dementia, leading to negative attitudes towards patients [5] and quality of care is dependent on positive provider attitudes.

Awareness and services among the people with Alzheimer's disease are essential to provide quality, cost-effective oriented healthcare, including dementia [19].Finally, students also discovered that hospital caregivers cannot offer adequate guidance because providers lacked specific dementia related care competencies. The number of hours of Alzheimer's disease training did not significantly influence students' dementia knowledge [5]. Factors that contribute to nursing student's knowledge regarding people with $\mathrm{AD}$, and the effect those knowledge have on providing quality care must be examined. Changes must be made in nursing education that will improve nursing students' knowledge towards people with $\mathrm{AD}$. Enhancing the current nursing curriculum using experiential learning methods might positively impact student knowledge [19].

Across many countries the provision of effective and appropriate care for people with Alzheimer's disease is a growing challenge. In Australia, it was projected that nearly 300,000 people had Alzheimer's disease related dementia out of a total population of 23 million in 2011. This number was anticipated to upsurge 900,000 in 2050, through a parallel rise required in the number of health professionals to care for this vulnerable population [4]. The quality of life as well as the practical status of people with Alzheimer's disease was affected by the quality of their care in a range of health care environments, including acute and community care. Adequate knowledge of Alzheimer's disease among health care team has been presented to affect critical issues in maintenance, such as the timing of diagnosis and the following application of interventions and the quality of care environments [7,34], which are in turn, linked to improved patient outcomes $[26,8,22]$.

The association concerning the knowledge of dementia and quality of maintenance in the acute care setting was piloted in Australia and it was found that lack of knowledge about dementia and the possible sources of patient confusion, and severe care of cognitively impaired people was mentioned to be inconsistent and to have emphasized safety at the expense of wellbeing and dignity. Caregivers displayed generally negative attitudes towards people with dementia and nurses expressed reluctance to care for patients with Alzheimer's disease because they found it unsatisfactory. Both of these sets of authors concluded that nursing student's education and training was dangerous to improve the excellence of care conventional by a person with Alzheimer's disease while in acute care [14]. Nursing students are more likely to encounter older persons with Alzheimer's disease during their management of patients in the clinical area with Alzheimer's disease and in assisting their caregivers which is important to evaluate the nurse's level of knowledge.

An additional variable of interaction was the degree to which the nursing students were cognizant of their level of knowledge about AD.[28] Hence, it is essential that nursing students are fortified with adequate Alzheimer's disease knowledge to deliver the holistic care to the elderly population. Conversely, published substantiation clearly proves that health care operation among people with Alzheimer's disease is limited in India [27]. Most of the studies from India mainly focused on prevalence rates from different regions of India [30, 31].

Currently, however there are studies that examined nurses' knowledge towards dementia are limited [13]. Therefore, it is precarious to evaluate nursing students' level of knowledge toward Alzheimer's disease. The purpose of the study is to assess the level of knowledge about $\mathrm{AD}$ related to aging and Dementia among nursing students.

An additional purpose is to assess the relationship between student's level of knowledge on $\mathrm{AD}$ and related Dementia and to investigate the relationship between selected demographic variables and the knowledge variables. The outcomes may be responsible for the evidence to ascertain the scarcities in the nursing curricula. Thus, the present study aimed to assess nursing students' general knowledge toward Alzheimer's disease and their capability in functioning towards elderly with Alzheimer's disease.

\section{AIM OF THE STUDY}

The aim of the study is to assess the level of knowledge regarding Alzheimer's disease among nursing students.

\section{OBJECTIVES OF THE STUDY}

1. To assess the level of knowledge regarding Alzheimer's disease among nursing students.

2. To find out the association between the level of knowledge and selected demographic variables.

\section{RESEARCH HYPOTHESIS}

$\mathrm{H}_{1}$ There is statistically significant difference between the pretest and post-test knowledge scores of nursing students after the teaching program.

$\mathrm{H}_{2}$ There is statistically significant association between the level of knowledge and selected demographic variables of nursing students.

\section{OPERATIONAL DEFINITIONS}

\section{Teaching program:}

It refers to the systematic, organized and planned teaching module prepared by the investigator which is given to the 
nursing students in order to enhance their knowledge regarding Alzheimer's disease.

\section{Knowledge:}

It refers to the responses given to the questions asked by the investigator regarding Alzheimer's disease to the nursing students which is measured by structured tool.

\section{ASSUMPTIONS}

1. Nursing students may have basic knowledge regarding Alzheimer's disease.

2. The knowledge about Alzheimer's disease among nursing students may help them to identify and manage the elderly at right time.

3. The teaching program may help the nursing students to improve their level of knowledge.

\section{CONCEPTUAL FRAMEWORK}

A conceptual framework is a group of concepts and a set of propositions that spell out the relationship between them. The overall purpose is to make scientific findings meaningful and generalized. Concepts refers to those words describing mental images of phenomena.

Polit and Hungler states that conceptual framework is made of inter related concepts that are assembled together in some rationale scheme by virtue relevance to a common thing. It is a plan that helps to stimulate research and extension of knowledge by providing both direction and impetus.

The conceptual model used for the present study is based on Sister Callista Roy's adaptation theory (Roy, 1989).The Roy's adaptation model focusses on the response to the adaptive system to a constantly changing environment. The System is defined as a set of parts connected to function as a whole for some purpose, and it does so by virtue of the interdependence of its parts. Problems in adaptation arise when the adaptive system is unable to cope with and respond to constantly changing stimuli from the internal and external environments in a manner that maintains the integrity of the system.

The person identified as a bio-psycho social being and as an adaptive system. Adaptive means that human system has the capacity to adjust effectively to changes in the environment and in turn affect the environment (Andrews and Roy, 1991) [15].

In the present study, adaptive system is the teacher who has the ability for effective management of older adults suffering from Alzheimer's disease and the early detection and their referral services towards the nursing students.

\section{METHODOLOGY}

Quasi-experimental study was done among nursing students at Saveetha College of Nursing, Saveetha University, India. This study was aimed to examine nursing students' knowledge towards Alzheimer's disease related Dementia and the interrelationships between the research variables.

Figure 1 Diagrammatic representation of Research methodology

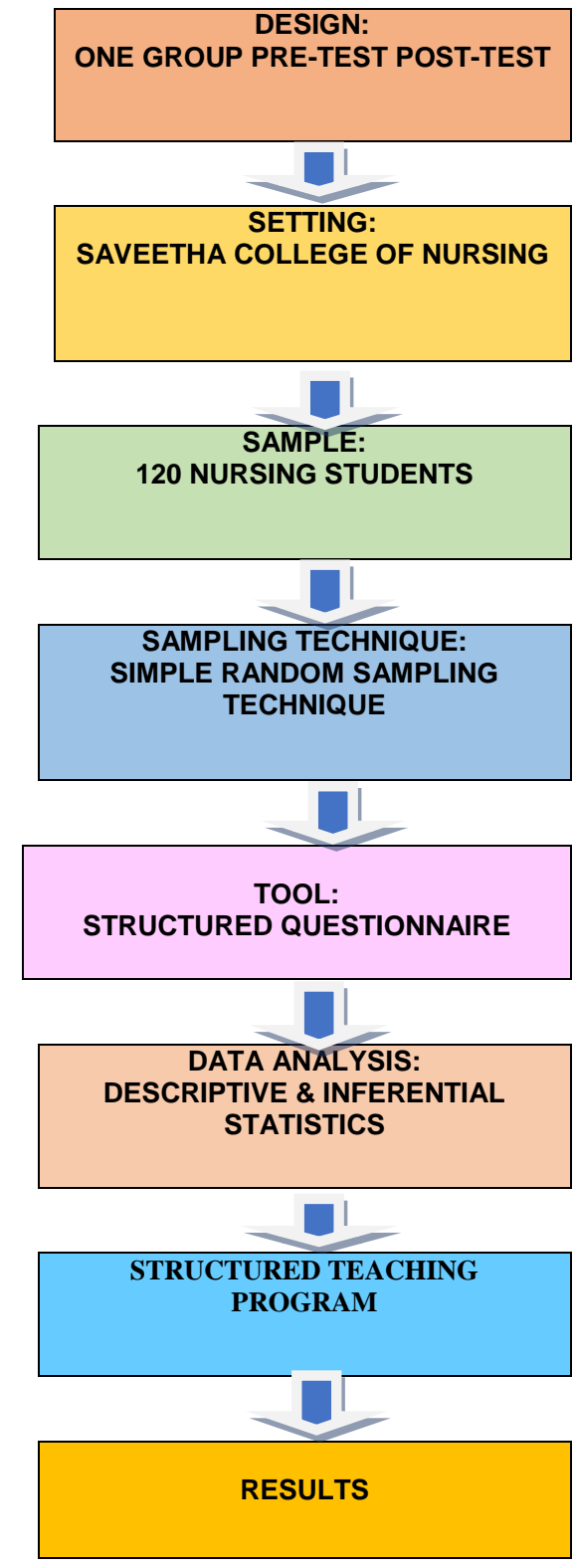

\section{Research approach:}

The research approach explains the basic procedure to conduct the research process. Quasi-experimental study was considered as appropriate research approach for the present study. 


\section{Research design}

According to Polit and Hungler (1999), a research design is the overall plan for addressing a research question. The research design selected for the study was one group pre-test and post-test.

\section{Setting of the study}

Setting refers to the area where the study conducted and it is the physical location in which data collection takes place in a study. This present study was conducted in Saveetha College of nursing, Chennai, South India.

Saveetha college of Nursing has well-established infrastructure by experienced, competent faculty members and innovative teaching methods to meet the global demand of the nurses. Institute has 1000 bedded multi-specialty hospital within the campus, thus no need for the students to go out for their clinical experience.

\section{Population}

Population refers to the entire aggregation of samples that meets a designed criterion. All nursing students studying at Saveetha College of nursing in Chennai during the time of data collection is considered as population. The sample for the present study selected through a Simple random sampling method from the class attendance register. Nursing students from Basic Nursing (B.Sc.), Post basic (PBSc) and Master's degree (M.Sc.) from all specialties and those willing to participate were included since they did not have clinical exposure to the patients with Alzheimer's disease. There were 138 students those were enrolled in the study.

However, 18 students were not included because of incomplete responses, not willing to participate and who were absent during the particular day of data collection. Hence, final sample comprised of 120 nursing students.

\section{Sample and sampling technique}

Sample refers to the subset of population selected to participate in the study. Sampling refers to the process of selecting a portion of population to represent the entire population.

The sample of the study consists of 120 nursing students studying in the same college.

Simple random sampling technique was used for the study to select the sample.

\section{Criteria for sample selection}

\section{Inclusion criteria}

Nursing students

o Who were willing to participate in the study.

- Who were available during the period of data collection

$\circ$ Who were able to read and understand English?

\section{Exclusion criteria}

Nursing students

○ Who were studying in the same college.
- Who were not willing to participate in the study.

- Who were absent on the particular day.

\section{Description of the instrument}

The instrument used for this study consists of two parts.

Part one: Student's demographic data includes age, gender, educational qualification, Family Monthly income of the family, Family system, Place of residence, Leisure time, Number of children in the family and Parents education. The detailed version of the demographic data schedule is given in table 1 .

Part two: Alzheimer's disease Knowledge Scale (ADKS) which includes nursing students' level of knowledge. This validated tool comprised of 30 items with true/false responses. One mark awarded for every correct response, zero for the wrong response. Henceforth, the total number of marks in the knowledge scale ranged from 0 to 30 . The above mentioned Knowledge Scale was selected for the present study since it is easy to use and has good psychometric properties with high internal consistency (.71).

The Alzheimer's disease Knowledge Scale (ADKS) identified the level of knowledge using the following domains:

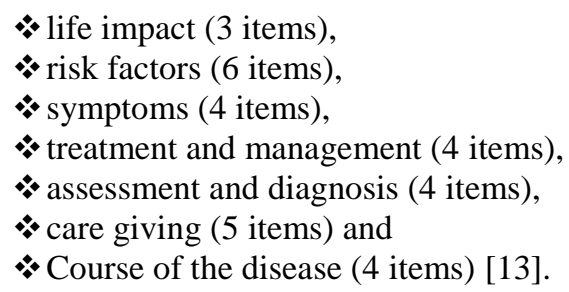

Part three: The structure teaching program is based on the following areas:

$$
\begin{aligned}
& >\text { Role play } \\
& >\text { Charts } \\
& >\text { Pictures } \\
& >\text { Pamphlets }
\end{aligned}
$$

\section{SCORING AND INTERPRETATION}

The subjects were asked to rate each item on a 2-point Likert scale ranging from 0for wrong response to 1 for correct response. All the students participated in the study actively, therefore the final study comprised of 120 nursing students from all degrees in College of Nursing. The first step toward improving Alzheimer's disease related Dementia knowledge among the nursing students is to assess their current level of knowledge using a reliable tool that will identify knowledge gaps. There are a number of assessment tools that have been developed over the past decades. [32]

A more recent tool, the Alzheimer's disease Knowledge Scale (ADKS) [9], was promising and showed good psychometric properties. Originally used by its developers [10], two recently published articles have confirmed the utility of the ADKS in this context $[16,24]$. The level of knowledge was assessed on 
Alzheimer's disease among nursing students prior to the implementation of knowledge programs as a baseline and to identify the gaps in knowledge level. And then the effectiveness of an Alzheimer's disease knowledge education program was assessed [17, 25, and 34]. However, previous studies have shown that the health care team responsible for the diagnosis of Alzheimer's disease and the implementation of treatment plans, care of old aged patients have deficits in the knowledge of Alzheimer's disease and related dementia.

\section{ETHICAL APPROVAL}

An official approval was obtained from the Principal, College of Nursing and the Research Ethical committee of the Saveetha College of Nursing, Saveetha University. The data obtained was treated confidentially and anonymously. Permission was sought to use the knowledge scale from the authors who developed them. A covering letter was included with the questionnaire and distributed to the students enlightening the aims and purposes of the study.

Students were also knowledgeable that partaking was voluntary and confidentiality would be upheld. No consent form was required as returning the questionnaire was a voluntary way to opt in the study (Polit and Beck, 2010) [12]. A hard copy of the questionnaire was distributed to the students and in order to maintain anonymity, participants were assured about their right to withdraw from the study at any time.

\section{DATA COLLECTION PROCEDURE}

The investigator obtained permission from Principal, Saveetha College of Nursing to conduct the study among the Nursing students from the same college. A pilot study was conducted to test the feasibility and applicability of the tool. The pilot study as carried out on ten subjects who were excluded from the main study. The results of the pilot study helped in refining some of the questions and thus no major changes have been done. The investigator introduced self to the students and explained about the aims, objectives, methods and importance of the study to all participants and ascertained the willingness of the participants. And thus the investigator explained the study to all the participants and following that the questionnaires were administered.

The main study was conducted on the Alzheimer's day, September month. The study was done by choosing 120 samples by using Simple random sampling technique. The pretest was conducted by using validated structured questionnaire (ADKS), and assured reading the confidentiality of the data. The time duration allowed was 15-20 minutes for the participants to complete the questionnaires. After the pretest samples were asked to gather and sit comfortably in a room where there was adequate lighting facilities and ventilation.

A structured teaching program has been performed before them with adequate AV aids for about 30 minutes.
Then, once again the questionnaires were distributed to each batch of students separately after the teaching program for the post-test. The main aim of the teaching program was to impart knowledge level regarding the Alzheimer's disease and related dementia and to give an awareness of old aged patient's life factors involving the biological, psychological and sociocultural aspects were discussed in the form of role play, using charts and pictures and pamphlets. At the end of the program, 30 minutes given for discussion.

\section{DATA ANALYSIS AND STATISTICAL METHODS}

The statistical methods used for data analysis were descriptive and inferential statistics. Descriptive statistics includes Number, percentage, mean, median, standard deviation and Inferential statistics includes correlation coefficient, Pearson's Correlation, Chi-square test $\left[\chi^{2}\right]$. Before data analysis, responses of the negative statements were rear coded. Descriptive and inferential statistics used to conclude the significant differences between the contributors mean knowledge scores. The data was imputed and analyzed using Statistical Package of Social Studies [SPSS] version 21.0. Statistical significance considered at $\mathrm{p}<0.05$.

The plan of data analysis is as follows:

Descriptive statistics:

25 The responses of the items in part-one demographic variables was summarized in number and percentage.

es Statistical differences in the pre-test and post-test were assigned as mean, standard deviation and mean percentage.

Inferential statistics:

es Chi-square value was used to work out in order to find out the association between the demographic variables such as age, gender, marital status, religion, family type, place of residence, education, occupation, family income, with the pre-test and post-test scores of the level of knowledge among the nursing students.

\section{RESULTS}

The present cross-sectional study on Alzheimer's disease comprised of nursing students from the same college $(\mathrm{N}=120)$, and from various areas of degree namely Bachelor degree, Post basic degree and Master degree students.

Table 1 Description of socio-demographic variables among the nursing students.

$\mathrm{N}=120$

\begin{tabular}{llll}
$\begin{array}{l}\text { Demographic } \\
\text { variables }\end{array}$ & category & \multicolumn{2}{c}{ NumberPercent \% } \\
Age group & $18-30$ & 120 & 100
\end{tabular}




\begin{tabular}{|c|c|c|c|}
\hline Gender & $\begin{array}{l}\text { Male } \\
\text { Female }\end{array}$ & $\begin{array}{l}18 \\
102\end{array}$ & $\begin{array}{l}15 \\
85\end{array}$ \\
\hline Educational degree & $\begin{array}{l}\text { B.Sc. N } \\
\text { M.Sc. N } \\
\text { PBSc N }\end{array}$ & $\begin{array}{l}72 \\
14 \\
34\end{array}$ & $\begin{array}{l}60 \\
11.67 \\
28.3\end{array}$ \\
\hline Family system & $\begin{array}{l}\text { Nuclear } \\
\text { Joint }\end{array}$ & $\begin{array}{l}88 \\
32\end{array}$ & $\begin{array}{l}73.3 \\
26.67\end{array}$ \\
\hline Leisure time & $\begin{array}{l}\text { Television } \\
\text { Story } \\
\text { books\& TV } \\
\text { Playing } \\
\text { \&others }\end{array}$ & $\begin{array}{l}80 \\
22 \\
18\end{array}$ & $\begin{array}{l}66.67 \\
18.3 \\
15\end{array}$ \\
\hline Family income/month & $\begin{array}{l}\text { Up to } 5000 \\
5001-10000 \\
\text { more than } \\
10000\end{array}$ & $\begin{array}{l}13 \\
29 \\
78\end{array}$ & $\begin{array}{l}10.8 \\
24.16 \\
65\end{array}$ \\
\hline Place of residence & $\begin{array}{l}\text { Urban } \\
\text { Rural }\end{array}$ & $\begin{array}{l}84 \\
36\end{array}$ & $\begin{array}{l}70 \\
30\end{array}$ \\
\hline $\begin{array}{l}\text { Number of children in } \\
\text { family }\end{array}$ & $\begin{array}{l}\text { one } \\
\text { two } \\
\text { three \& } \\
\text { above }\end{array}$ & $\begin{array}{l}12 \\
80 \\
28\end{array}$ & $\begin{array}{l}10 \\
66.67 \\
23.3\end{array}$ \\
\hline Father education & $\begin{array}{l}\text { Non-literate } \\
\text { Elementary } \\
\text { level } \\
\text { High school } \\
\text { Hr. sec \& } \\
\text { above }\end{array}$ & $\begin{array}{l}5 \\
36 \\
31 \\
48\end{array}$ & $\begin{array}{l}4.16 \\
30 \\
25.8 \\
40\end{array}$ \\
\hline Mother education & $\begin{array}{l}\text { Non-literate } \\
\text { Elementary } \\
\text { level } \\
\text { High school } \\
\text { Hr. sec \& } \\
\text { above }\end{array}$ & $\begin{array}{l}5 \\
28 \\
32 \\
55\end{array}$ & $\begin{array}{l}4.16 \\
23.3 \\
26.67 \\
45.83\end{array}$ \\
\hline
\end{tabular}

Table 1 represents the demographic variables of the study participants $(\mathrm{N}=120)$, which included B.Sc. (N) $72(62 \%)$, Post basic 34(28.3\%) and Master degree 14 (11.67\%). Among the participants, most of them were females $102(85 \%)$ and ranged in age from 19-30 years, with two thirds under 25 years of age. A majority of the participants was from urban background $(70 \%)$ and the major proportion $(60 \%)$ of participants from BSC (N) was slightly higher than participants from MSC (N) and Post basic Nursing students (11.67\% and 28.3\%) respectively. Most of the students had previously seen patients with $\mathrm{AD}$, comparatively very few had actually worked with such patients.

$\begin{array}{cccc}\text { Table } 2 & \text { PRE-TEST } & \text { AND POST-TEST } & \text { LEVEL OF } \\ \text { KNOWLEDGE } & \text { ON } & \text { ALZHEIMER'S } & \text { DISEASE } \\ \text { AMONG NURSING STUDENTS } & \end{array}$

$\mathrm{N}=120$

\begin{tabular}{|l|c|c|c|c|}
\hline \multirow{2}{*}{$\begin{array}{l}\text { Level of } \\
\text { Knowledge }\end{array}$} & \multicolumn{2}{|c|}{ Pre-test } & \multicolumn{2}{c|}{ Post-test } \\
\cline { 2 - 5 } & $\begin{array}{c}\text { Knowledge } \\
\text { Number }\end{array}$ & $\%$ & $\begin{array}{c}\text { Knowledge } \\
\text { Number }\end{array}$ & $\%$ \\
\hline Inadequate & 92 & 77 & 2 & 1 \\
\hline Moderate & 24 & 20 & 10 & 9 \\
\hline Adequate & 4 & 3 & 108 & 90 \\
\hline
\end{tabular}

Table-2 mentions the pre-test and post-test scores among respondents level of knowledge on Alzheimer's disease. The highest score was $77 \%$ on inadequate knowledge out of 120 samples and $20 \%$ had moderate knowledge whereas only four (3\%) of the respondents had adequate pre-test knowledge on Alzheimer's disease. In the aspect of post-test among respondents level of knowledge, the highest score was $90 \%$ on adequate knowledge and 10 (9\%) had moderate knowledge whereas only two (1\%) respondents had inadequate pre-test knowledge on Alzheimer's disease.

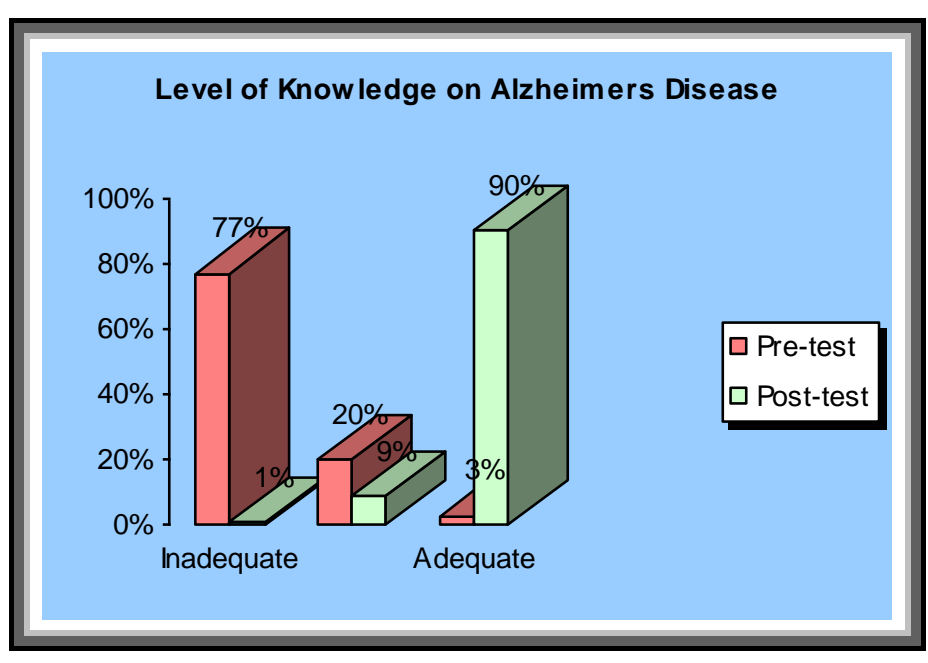

Table 3 MEAN KNOWLEDGE SCORES ON ALZHEIMER'S DISEASE AMONG NURSING STUDENTS DURING PRE-TEST

\begin{tabular}{|c|l|c|c|c|c|}
\hline No & $\begin{array}{l}\text { Knowledge } \\
\text { aspects }\end{array}$ & Statements & $\begin{array}{l}\text { Max } \\
\text { score }\end{array}$ & Mean & SD \\
\hline 1 & Life impact & 3 & 3 & 1.68 & 0.76 \\
\hline 2 & Risk factors & 6 & 6 & 2.74 & 1.32 \\
\hline 3 & Symptoms & 4 & 4 & 2.25 & 0.90 \\
\hline 4 & $\begin{array}{l}\text { Treatment } \\
\text { and } \\
\text { management }\end{array}$ & 4 & 4 & 2.3 & 1.05 \\
\hline
\end{tabular}




\begin{tabular}{|c|l|c|c|c|c|}
\hline 5 & $\begin{array}{l}\text { Assessment } \\
\text { and diagnosis }\end{array}$ & 4 & 4 & 2.53 & 0.92 \\
\hline 6 & Care giving & 5 & 5 & 2.74 & 1.13 \\
\hline 7 & $\begin{array}{l}\text { Course of the } \\
\text { disease }\end{array}$ & 4 & 4 & 2.45 & 0.93 \\
\hline & $\begin{array}{l}\text { Combined } \\
\text { aspects }\end{array}$ & 30 & 30 & 16.6 & 3.46 \\
\hline
\end{tabular}

Table-3 depicts the aspect wise pre-test mean knowledge scores on Alzheimer's disease among nursing students. The highest mean score was seen regarding the Risk factors, Symptoms \& Assessment diagnosis and the lowest mean score was seen in the Life impact. The treatment and Management, Care giving showed mean score of $15.4 \pm 2.98$.

However, the respondents demonstrated poor level of knowledge in the following domains such as life impact, Risk factors, Symptoms \& Assessment diagnosis, and Treatment \& Management and Care giving. Similarly, overall mean score out of 30 suggested that participants had inadequate knowledge regarding Alzheimer's disease related to dementia.

Table 4 MEAN KNOWLEDGE SCORES ON ALZHEIMER'S DISEASE AMONG NURSING STUDENTS DURING POSTTEST

\begin{tabular}{|c|l|c|c|c|c|}
\hline No & $\begin{array}{l}\text { Knowledge } \\
\text { aspects }\end{array}$ & Statements & $\begin{array}{l}\text { Max } \\
\text { score }\end{array}$ & Mean & SD \\
\hline 1 & Life impact & 3 & 3 & 1.77 & 0.75 \\
\hline 2 & Risk factors & 6 & 6 & 3.07 & 1.35 \\
\hline 3 & Symptoms & 4 & 4 & 2.32 & 0.92 \\
\hline 4 & $\begin{array}{l}\text { Treatment } \\
\text { and } \\
\text { management }\end{array}$ & 4 & 4 & 2.60 & 1.00 \\
\hline 5 & $\begin{array}{l}\text { Assessment } \\
\text { and diagnosis }\end{array}$ & 4 & 4 & 2.54 & 1.02 \\
\hline 6 & & & & & \\
\hline
\end{tabular}

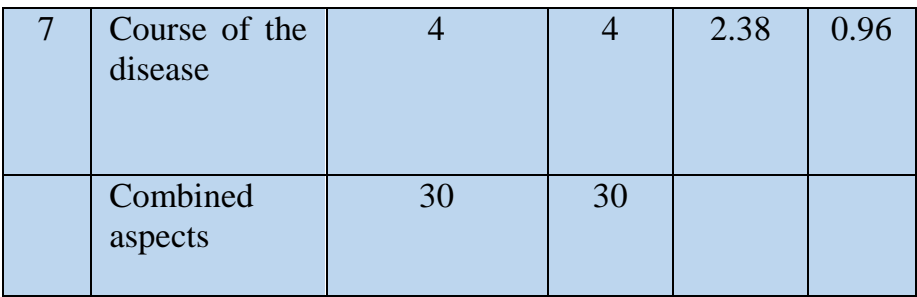

Table-4 presents the aspect wise post-test mean knowledge scores on Alzheimer's disease among nursing students. The highest mean score was seen regarding the Risk factors, Treatment \& Management, Care giving and the lowest mean score was seen in Life impact, Symptoms and Course of the disease which is significant at the level of $p<0.01$.

Table 5 OVERALL PRETEST AND POSTTEST MEAN KNOWLEDGE ON ALZHEIMER'S DISEASE AMONG NURSING STUDENTS

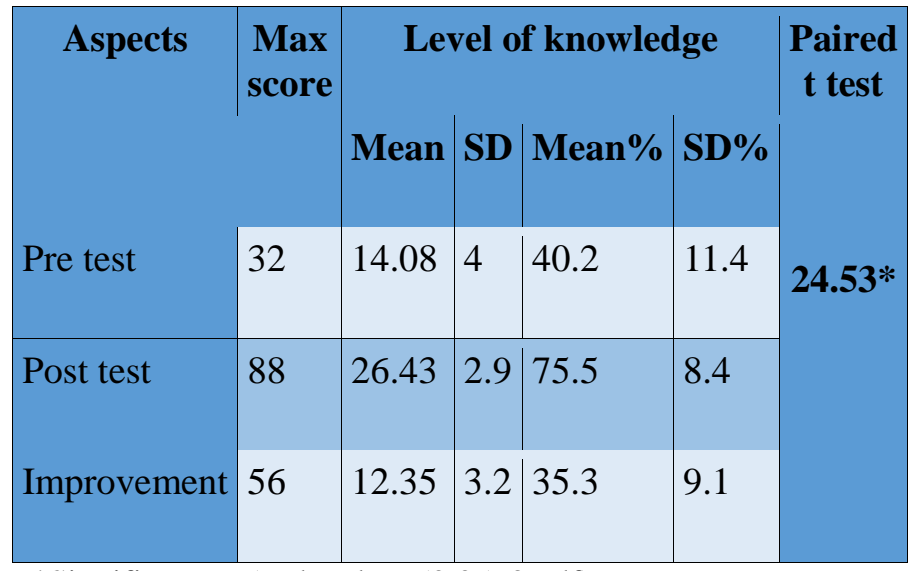

*Significant at $5 \%$ level $\mathrm{t}(0.05,39 \mathrm{df})$

Table 5 shows the overall pre-test and post-test mean knowledge on Alzheimer's disease. The mean pretest score was found to be $40.2 \pm 11.4$ and the post test score was found to be $75.5 \pm 8.4$ and the obtained $t$ value was found to be 24.53, at the level of $\mathrm{p} \mathrm{d}=0.05$ and the first hypothesis was proved to be correct.

\section{DISCUSSION}

The focus of this study was to examine nursing students' level of knowledge towards Alzheimer's disease. The findings of the study showed inadequate knowledge among nursing students toward Alzheimer's disease related Dementia. However, they hold encouraging little knowledge toward Alzheimer's disease related to dementia. In the present study, the overall mean score of Alzheimer's disease level of knowledge was $40.2 \pm 11.4$, out of 30 suggested that participants had insufficient knowledge regarding Alzheimer's disease. Similarly, knowledge was inadequate in the domain 
of the ADKS such as 'Life impact' $(1.77 \pm 0.75)$. However, the mean score of the present study was significantly higher in the post-test knowledge of Alzheimer's disease among nursing students $(75.5 \pm 8.4)[11]$. In general, nursing students with high level of knowledge on Alzheimer's disease related dementia are able to provide quality of care to the people with same condition admitted in the hospital or at community level. This was consistent with previous studies that found substantiate relationship between knowledge of Alzheimer's disease and quality of care [6].

The findings of the present study showed the significant difference related to mean knowledge scores between master degree, Post basic degree, and bachelor degree students. The mean knowledge score for the master and post basic degree students slightly higher when compared to the students from bachelor degree. A recent study observed that knowledge of Alzheimer's disease related to dementia was higher among students in the Master of Science in nursing program compared to the Associate of Science in nursing students [19]. The Pearson correlation coefficient test was revealed that a negative relationship existed between age and knowledge $(\mathrm{r}=0.32 ; \mathrm{p}<0.001)$ towards Alzheimer's disease. The students studying Master's degree scored higher on the total knowledge scale compared to the other degrees students such as Post basic and Basic Nursing degree.

Nursing students are often fearful of the behaviors exhibited by people with Alzheimer's disease. They need to be better prepared and supported when providing care for old aged people with Alzheimer's disease and related Dementia. As the next century approaches and the number of aging persons with Alzheimer's disease increases, social work educators, researchers, practitioners, administrators, and policymakers must examine their practice in light of the profession's mandate to maintain or enhance the bio psychosocial functioning of patients. When they do, they will see the need to serve this vulnerable population.

\section{STUDY LIMITATIONS}

The study is limited by its limited population, Small sample size and by the instrument used. Moreover, the present sample comprised predominantly by the women. Hence, we could not examine the gender differences. Because of limitations faced by the investigators, the study population was restricted to a single nursing institution in India and only nursing students. Further, quantitative approach was adopted for this study. Thus, the results may not be generalizable. In addition, the findings are based on a self-report screening instrument.

Despite these limitations, the investigator consider that this study comprise significant findings for investigators as well as nurse educationalists in expressing the curriculum to nurture knowledge in caring of elder people with Alzheimer's disease towards the positive development. In the future, broadening sample range can generalize this result to male psychiatric nurses, nurses from different psychiatric hospitals, or nurses at general short-term hospitals.

\section{IMPLICATIONS FOR NURSING EDUCATION, PRACTICE, AND RESEARCH}

Results of this study, while not generalizable to other nursing programs, emphasize the need for nursing educators to evaluate the effectiveness of their role, as well as the overall curriculum, in preparing students for the complexities involved in caring for the elderly and those with Alzheimer's disease. Faculty should act as mentors with nursing students by role modeling quality practice with assigned elders and particularly those with AD. Gerontological content integrated throughout the curriculum without a clearly identified plan may not be sufficient in preparing nursing students to care for the elderly and those with age-related conditions such as AD. As the body of knowledge in gerontology expands, there will be a need for comprehensive curriculum planning directed toward incorporating specific gerontology content and clinical experiences.

Students must have the opportunity to care for patients with $\mathrm{AD}$ when such clinical experiences are available. Effective role models in gerontological nursing must he encouraged. Also, there is also a need to develop outcome measures to evaluate the effectiveness of teaching strategies designed to provide students with a substantial gerontological knowledge base. Finally, it is strongly recommended that nursing programs should identify and implement essential gerontology content within the curriculum and develop mechanisms to track, update, and evaluate the content.

\section{CONCLUSION AND FUTURE DIRECTIONS}

The present study assesses the level of knowledge on $\mathrm{AD}$ and related Dementia among nursing students from various degrees studying in the same college. The results revealed that there was inadequate knowledge among the nursing students to give care among the same population. There was statically significant difference between the pre-test and post-test knowledge scores of nursing students after administering the education program. There was statistically significant association between the level of knowledge and selected socio-demographic variables of nursing students such as age, gender, educational qualification, Family monthly income, Family system, place of residence, Leisure time, Number of children in the family and Parents education.

The study highlights the need for studies with rigorous methods to determine evidence based practice for all those working with people with Alzheimer's disease in order to provide effective care and improve their quality of life. It is concluded that the present study had an inadequate knowledge towards people with dementia.

Most of the findings were positive, demonstrating the potential to improve students' knowledge, and comfort level, however methods and evaluation were not always sufficiently reported, 
making them difficult to use or replicate. However, they hold encouraging attitudes towards patients with Alzheimer's disease giving space to improve their knowledge related to it. Also, emphasizes basic nursing education is not sufficient to prepare nurses to cope with problems in daily nursing practice.

Additionally, the results confirm the most obvious method of accomplishing the required awareness and knowledge in strengthening the Alzheimer's disease and related dementia, old age problems. We recommend a multidisciplinary intervention that not only focuses on using the newly developed evidence-based scales, but also focuses on improved education and knowledge programs for nursing students. As a result, it should be of priority and on overcoming misconceptions to provide quality care.

The aspect wise pre-test knowledge score was $1.68 \pm$ 0.76 in the area of Life impact and in the area of Risk factors and care giving was found to be $2.74 \pm 1.32$ and in the area of symptoms and treatment and management was found to be $2.25 \pm 0.90$. At the same time aspect wise post-test knowledge score was $1.77 \pm 0.75$ in the area of Life impact and in the area of risk factors was found to be $3.07 \pm 1.35$ and in the area of symptoms was found to be $2.32 \pm 0.92$. There was significant association found between the pre-test knowledge level and selected demographic variables such as age, participant's degree of the study.

There was significant association found between the post-test knowledge level and selected demographic variables such as age, participant's degree, Family system, Place of residence and Parents education. Similarly, overall mean score $40.2 \pm$ 11.4 (out of 30) suggested that the study participants had inadequate knowledge regarding Alzheimer's disease and related dementia.

\section{RECOMMENDATIONS}

Based on the findings of this study, the following recommendations are suggested:

1. Development and implementation of public awareness campaigns about the Alzheimer's disease and the services available to help persons with such problems within the community in public areas like theaters, malls and throughout all media channels including $\mathrm{TV}$, radio, internet, SMS messages... etc.

2. Development of awareness programs specific for school and college students and other high risk groups about the Alzheimer's disease urgent need to meet those groups' unique needs.

3. Develop and implement programs and services for the reduction of social and mental health consequences of Alzheimer's disease, including preventive treatment, rehabilitation and social reintegration.

4. Regular "stress coping strategies" sessions should be organized and implemented for high risk groups to help them and cope up with life stressors and to minimize the possibility of Alzheimer's disease.

5. More extensive data may be required to fully assess the status of Alzheimer's disease in a larger population in future.

\section{FUNDING}

This research received no specific grant from any funding agency in the public, commercial, or not for profit sectors.

\section{CONFLICT OF INTEREST}

The investigator declared that no potential conflict of interest with respect to the study, authorship and Publication of this article.

\section{ACKNOWLEDGMENT}

The author is grateful to the management and principal of College of Nursing, Chennai for the help rendered towards the completion of the study in a successful manner. Also, the author would like to extend their recognitions and thankfulness to all participants who voluntarily participated in the study and shared their experience.

\section{References}

1. Alzheimer's Foundation of America AFA, 2016.

2.Alzheimer's Association. (2013). Alzheimer's disease facts and figures. Alzheimer's and Dementia: The Journal of the Alzheimer's Association, 8, 131- 168. doi:10.1016/j.jalz.2011.02.004.

3. Alzheimer's Association. (2014). Strategic Plan. Retrieved from http://www.alz.org/about_us strategic plan.asp.

4. Australian Institute of Health and Welfare (2012).Dementia in Australia. Cat. No. AGE 70. Canberra: AIHW.

5. Baillie, L., Cox, J., \& Merritt, J. (2012). Caring for older people with dementia in hospital

Part one: Challenges. Nursing Older People, 24(8), 3337.

6. Bailey K (2000).Student awareness of Alzheimer's disease. Am J Alzheimers Dis Other Demen .15(6):375-378

7. Barrett J, Haley W, Harrell L, Powers R (1997). Knowledge about Alzheimers disease among primary care physicians, psychologists, nurses, and social workers. Alzheimer Dis Assoc Disord .11(2):99-106.

8. Borbasi S, Jones J, Lockwood C, Emden C (2006)Health professionals' perspectives of providing care to people with dementia in the acute setting: Toward better practice. Geriatr Nurs.27 (5):300-308.

9. Carpenter B, Balsis S, Otilingam P, Hanson P, Gatz 
M (2009).The Alzheimer's disease Knowledge Scale: Development and psychometric properties. Gerontologist .49(2):236-247.

10. Carpenter B, Zoller S, Balsis S, Otilingam P, Gatz M (2011).Demographic and contextual factors related to knowledge about Alzheimer's disease. Am J

Alzheimers Dis Other Demen. 26(2):121-126.

11. Das SK, Pal S, Ghosal MK (2012). Dementia: Indian scenario. Neurol. India. 60:618-24.

12. Denise F. Polit, Cheryl Tatano Beck (2010). Essentials of Nursing Research: Appraising Evidence .7th edition.Lippincott Williams \& Wilkins.

13. Dieckmann L, Zarit S, Zarit J, Gatz M (1988). The Alzheimer's disease Knowledge Test. Gerontologist .28(3):402-407.

14. Foreman P, Gardner I (2005).Evaluation of education and training of staff in dementia care and management in acute settings. In Edited by Services ACBDoH. Melbourne, Victoria: Aged Care Branch.

15. Heather A Andrews and Callista Roy (1991). The Roy adaptation model: the definitive statement.Norwalk, Conn.: Appleton \& Lange.

16. Hudson J, Pollux P, Mistry B, Hobson S (2012).Beliefs about Alzheimer's disease in Britain. Aging Ment Health .16(7):828-835.

17. Jackson E, Cherry K, Smithman E, Hawley K (2008): Knowledge of memory aging and Alzheimer's disease in college students and mental health professionals. Aging Ment Health.12 (2):258-266.

18. Jefferson A.L., Cantwell N.G., Byerly L.K., Morhardt, D. (2012). Medical studen Education program in Alzheimer's disease: The PAIRS Program. BMC Medical Education, 12(80). Doi: 10.1186/1472-6920-12-80.

19. Low L, Anstey K (2009).Dementia literacy: Recognition and beliefs on dementia of the Australian public. Alzheimers and Dementia .5:4349.

20. Marco Canevelli, Martina Valletta, Alessandro Trebbastoni, Giuseppe Sarli,

Fabrizia D'Antonio, Leonardo Tariciotti, Carlo de Lena and Giuseppe Bruno (2016).Sundowning in

Dementia: Clinical relevance, Pathophysiological determinants, and therapeutic approaches. Frontiers in Medicine. Volume 3.Article 73.

21. Millard F, Kennedy L, Baune B (2011). Dementia: opportunities for risk reduction and early detection in general practice. Aust J Prim Health.17:89-94.

22. Millard F, Baune B (2009).Dementia - who cares? A comparison of community needs and primary care services. Aust Fam Physician, 38(8):642-649.

23. Moyle W, Borbasi S, Wallis M, Olorenshaw R (2011).Acute care management of older people with dementia: A qualitative perspective. J Clin Nurs .20(3-4):420-428

24. Nordhus I, Sivertsen B, Pallesen S (2012).Knowledge about Alzheimer's disease among Norwegian psychologists: The Alzheimer's disease Knowledge Scale. Aging Ment Health .16(4):521-528.

25. Peterson D, Berg-Weger M, McGillick J, Schwartz L (2002).Basic care 1: The effect of dementia-specific training on certified nursing assistants and other staff. Am J Alzheimers Dis Other Demen. 17 (3):154-164.

26. Perry M, Draskovic I, van Achterberg T, Borm G, van Eijken M, Lucassen P, et al (2008). Can an EASYcare based dementia training programme improve diagnostic assessment and management of dementia by general practitioners and primary care nurses? The design of a randomized controlled trial. BMC Health Serv Res.8:71.

27. Raina SK, Razdan S, Pandita KK (2010). Prevalence of dementia in ethnic Dogra population of Jammu district, North India: A comparison survey. Neurol Asia. 15:65-9.

28. Rebecca M. Edwards, Mary Ann Plant,Debra S. Novak, Colleen Beall, and Lorin A. Baumhover (1992).Journal of Nursing Education. Knowledge about Aging and Alzheimer's disease Among Baccalaureate Nursing Students. Vol. 31, No. 3

29. Royal College of Nursing. RCN (2011). Dementia Project -Survey of Practitioners [Internet]. London:RCN [cited May 20, 2014]. Available from: http://www.rcn.org.uk/development/practice/ dementia/rcn_demetia_project

30. Saini R, Alagh P, Carpenter B (2012). Nurses and Alzheimer's disease: A holistic perspective. Indian J Public Health. 56:318-9.

31. Saldanha D, Mani R, Srivastav K, Goyal S, Bhattacharya D (2010). An epidemiological study of dementia under the aegis of mental health program, Maharstra, Pune Chapter. Indian J Psychiatry. 52:131-9.

32. Spector A, Orrell M, Schepers A, Shanahan N (2012).A systematic review of 'knowledge of dementia' outcome measures. Ageing Res Rev, 11(1):67-77.

33. Sullivan K, O'Conor F (2001).Providing education about Alzheimer's disease. Aging Ment Health, 5(1):5-13.

34. Sullivan K, Muscat T, Mulgrew K (2007).Knowledge 
of Alzheimer's disease amongst patients, carers, and non-carer adults: misconceptions, knowledge gaps, and correct beliefs. Top Geriatr Rehabil, 23(2):148159

35. WHO (2012). Dementia: A public health priority [Internet].Geneva: WHO. Available from: http://apps.who.int/iris/bitstream/1 0665/75263/1/9789241564458eng,pdf

\section{AUTHORS PROFILE}

Ms. Agnes Monica Victor post graduated in
Psychiatric Mental Health Nursing, currently
employed in King Saud Bin Abdul Aziz
University for Health Sciences Riyadh,
Kingdom of Saudi Arabia. Actively involved in
teaching practical Nursing for the 17 years and
currently teaches Psychiatric Mental health
Nursing, theory and clinical courses.

